\title{
Artificial light disrupts the nearshore dispersal of neonate flatback turtles Natator depressus
}

\author{
Phillipa Wilson ${ }^{1,2, *}$, Michele Thums ${ }^{2}$, Charitha Pattiaratchii ${ }^{1}$, Mark Meekan ${ }^{2}$, \\ Kellie Pendoley ${ }^{3}$, Rebecca Fisher ${ }^{2}$, Scott Whiting ${ }^{4}$
}

\author{
${ }^{1}$ Oceans Graduate School and The UWA Oceans Institute, The University of Western Australia, 35 Stirling Highway, Crawley, \\ WA 6009, Australia \\ ${ }^{2}$ Australian Institute of Marine Science, Indian Ocean Marine Research Centre, The University of Western Australia (M096), \\ 35 Stirling Highway, Crawley, WA 6009, Australia \\ ${ }^{3}$ Pendoley Environmental, 12A Pitt Way, Booragoon, WA 6154, Australia \\ ${ }^{4}$ Marine Science Program, Department of Biodiversity, Conservation and Attractions, 17 Dick Perry Avenue, Kensington,
} WA 6151, Australia

\begin{abstract}
After emerging from nests, neonate sea turtles entering the water are thought to orientate away from shore using wave cues to guide them out to sea. Artificial light may interfere with this process, but the relative importance of natural and anthropogenic cues to the dispersal of hatchlings is unknown. Here, we used acoustic telemetry to track the movement of flatback turtle Natator depressus hatchlings dispersing through nearshore waters. Turtles dispersed in the presence and absence of artificial light through a receiver array where a range of oceanographic variables were measured. Turtle tracks were analysed using a full subsets generalised additive mixed model approach to identify the most important cues influencing the bearing, variance in bearing (a measure of the ability to orientate directly), rate of travel and time spent in the array. Artificial light reduced their swim speed by up to $30 \%$, increased the amount of time spent in nearshore waters (by 50 to $150 \%$ ) and increased the variance in bearing (100 to $180 \%$ more variable), regardless of oceanographic conditions. Under ambient conditions, ocean currents affected the bearing of hatchlings as they left the shore, but when light was present, this effect was diminished, showing turtles actively swam against currents in their attempts to move towards light. After accounting for the effects of currents on hatchlings dispersing under ambient conditions, turtles swam offshore by moving perpendicular to the coastline and did not appear to orient into incident wave direction. Overall, light disrupted the dispersal of hatchlings, causing them to linger, become disoriented in the nearshore and expend energy swimming against ocean currents.
\end{abstract}

KEY WORDS: Light pollution · Ocean currents · Acoustic telemetry · In-water movement · Hatchling · Vemco Positioning System

\section{INTRODUCTION}

Migration from natal habitats is a critical aspect of the early life history of many organisms (Dingle 1996). Understanding these movements and the consequences on population dynamics, genetics and distribution requires knowledge of the mechanisms in-

${ }^{*}$ Corresponding author: phillipa.wilson@research.uwa.edu.au volved (Clobert et al. 2012). However, collecting empirical data for very small organisms is challenging, so fundamental questions often remain for these early life-stages (Wikelski et al. 2007, Hays et al. 2016). Sea turtles are one such species, where the difficulties of directly tracking small turtle hatchlings in the wild (Thums et al. 2013) means that, at present,

() The authors 2018. Open Access under Creative Commons by Attribution Licence. Use, distribution and reproduction are unrestricted. Authors and original publication must be credited.

Publisher: Inter-Research · www.int-res.com 
little is known about how local oceanographic conditions influence their dispersal as they navigate away from the beach, with mostly laboratory experiments showing that they use wave cues to direct them offshore (Lohmann et al. 1990, 1995, Wyneken et al. 1990). Upon entering the ocean, they swim rapidly offshore in a behavioural phase termed the 'frenzy', which consists of continuous swimming for at least $24 \mathrm{~h}$ (Wyneken \& Salmon 1992) but can last for days (Salmon et al. 2009). This behaviour is thought to ensure the rapid transit of hatchlings from the edge of the beach to deeper waters, reducing their exposure to high densities of predators in nearshore environments (Wyneken \& Salmon 1992, Salmon et al. 2009). Given the difficulties of directly tracking hatchlings, the influence of cues such as coastal currents on nearshore trajectories of hatchlings has usually been assessed using modelling (Hays et al. 2010, Hamann et al. 2011, Scott et al. 2012, Robson et al. 2017). However, the advent of miniature acoustic tracking devices has offered the possibility of remote tracking of this early part of dispersal, allowing the influence of both natural (currents, wave action) and artificial (light) cues on this process to be assessed (Thums et al. 2016).

Thums et al. (2016) used small acoustic tags and a receiver array deployed along a shoreline to document the dispersal of hatchling turtles in a coral reef environment in north-western Australia. They found that current speeds greater than $0.30 \mathrm{~m} \mathrm{~s}^{-1}$ influenced the bearing of hatchlings dispersing under natural conditions at scales in the order of 10 to $150 \mathrm{~m}$. Similarly, another tracking study using the same technology has also shown that the trajectories, speed and orientation of hatchlings can be strongly influenced by ocean currents (Scott et al. 2014). Both of these studies focused on a single factor (current flow) when, in reality, hatchlings are likely to respond to a much wider range of cues during their dispersal offshore. For example, it is well known that visual cues aid hatchlings emerging from the nest to find the sea (Hendrickson 1958, Ehrenfeld \& Carr 1967). Hatchlings move away from elevated dark horizons (such as dunes) and towards the lowest, brightest horizon (Salmon et al. 1992, Limpus \& Kamrowski 2013, Pendoley \& Kamrowski 2015), and the importance of visual cues does not appear to cease once they enter the water (Avens \& Lohmann 2003, Thums et al. 2016). Once swimming, hatchlings are thought to switch to using waves (oceanic swell or wind-driven systems) to guide them further out to sea (Salmon \& Lohmann 1989, Wyneken et al. 1990, Lohmann \& Lohmann 1992, Okuyama et al. 2009), although hatchlings can still move offshore regardless of the direction of waves (Thums et al. 2016) and are also capable of navigating offshore under calm conditions (Abe et al. 2000, Pilcher et al. 2000), suggesting that multiple cues are likely to be employed to aid dispersal from the nearshore.

Importantly, artificial cues may override or disrupt this process of dispersal. For example, light pollution from anthropogenic sources is a pervasive threat, both on land and at sea, as it not only interferes with hatchlings finding the sea (Daniel \& Smith 1947, Verheijen 1985) but also with their in-water dispersal. Offshore lights can attract in-water dispersing hatchlings, causing them to linger around the light source at sea (Limpus et al. 2003, Thums et al. 2016), and onshore lights can slow down their in-water dispersal (Whelan \& Wyneken 2007, Harewood \& Horrocks 2008), increase their dispersion path (Witherington 1991) or even attract hatchlings back to shore (Truscott et al. 2017). This occurs because light pollution disrupts their response to natural visual cues (Verheijen \& Wildschut 1973), resulting in confusion and misorientation (Verheijen 1985, Pendoley 2005, Kamrowski et al. 2014a). On land, movement of hatchlings in a direction other than the sea often leads to death from predation, exhaustion, dehydration or being crushed by vehicles in urban areas (McFarlane 1963, Philibosian 1976), and it is likely that increasing their time spent in nearshore waters will also have consequences on hatchling fitness and survival.

The level of impact of artificial light is usually governed by its wavelength (Mrosovsky \& Carr 1967, Mrosovsky \& Shettleworth 1968). Light enriched in short wavelengths $(<600 \mathrm{~nm})$ is known to be highly attractive to hatchlings (Witherington 1992, Lohmann et al. 1997), including flatback turtle Natator depressus hatchlings (Pendoley 2005), thus longer wavelengths $(>600 \mathrm{~nm})$ are recommended for use in areas close to turtle nesting beaches when complete darkness is not an option (Witherington \& Martin 2003). Intensity and horizon elevation also significantly moderate the impact of artificial light on hatchling dispersal from nest to sea (Pendoley \& Kamrowski 2015).

Although Thums et al. (2016) demonstrated that artificial light interferes with the dispersal of turtle hatchlings in nearshore waters, the influence of different wavelengths of light and the relative importance of natural (wave direction, current flow) and artificial cues on this process has not yet been assessed. Here, we address this question for hatchlings of the flatback turtle. This species may be particularly susceptible to light pollution because it spends its entire life cycle in waters close to mainland 
Australia (Walker \& Parmenter 1990, Walker 1991), where light impacts are likely to be concentrated. Nesting occurs at sites with relatively low wave energy compared to other species (Santana Garcon et al. 2010, Pendoley et al. 2014), some of which are among the most light-exposed nesting areas in Australia (Kamrowski et al. 2012, 2014b). Consequently, the possibility that light attracts dispersing hatchlings in the water, and potentially impacts their survival, remains a key and currently unresolved issue for managing flatback turtle populations. This is particularly relevant in north-western Australia, where altered light horizons are common due to oil and gas platforms, port development and shipping related to mining operations located throughout the region (Limpus 2007).

\section{MATERIALS AND METHODS}

\section{Study site}

This study was conducted between 8 and 10 February 2016 during the new moon phase, after moon set (obtained from Geoscience Australia (www.ga.gov. $\mathrm{au} / \mathrm{geodesy/astro/moonrise.jsp)} \mathrm{during} \mathrm{the} \mathrm{peak}$ flatback turtle hatchling season (January to February), in the nearshore zone (up to $300 \mathrm{~m}$ from shore) on Thevenard Island, approximately $30 \mathrm{~km}$ offshore from the mainland of Western Australia (Fig. 1). Nesting occurs around the entire island but is concentrated on the south-eastern beaches. The north-western side of the island was selected for the study because this site was least affected by existing sources of artificial light on and around the island. These sources included those from nearby oil and gas developments near Onslow (25 km to the southeast) and Barrow Island (80 $\mathrm{km}$ to the northeast). The intensity of these light sources was measured with a digital allsky (Sky42) camera (see Supplement 1 at www.int-res.com/articles/suppl/m600 p179_supp/ for details).

\section{Tracking array}

Turtle hatchlings were tracked following the approach of Thums et al. (2016). An array of $36(6 \times 6)$ omnidi- rectional acoustic receivers (Vemco VR2W) was deployed $30 \mathrm{~m}$ apart, with the first line of receivers starting approximately $50 \mathrm{~m}$ from shore (Fig. 1) to calculate positions of hatchlings instrumented with V5 acoustic transmitters (Vemco) as they moved through the nearshore zone (see Supplement 1 for details of receiver spacing and range testing).

A Teledyne RDI acoustic Doppler current profiler (ADCP) was deployed in the middle of the array to measure current speed and direction, wave period, height and direction, and water temperature and depth. The current speed and direction and water depth and temperature were measured every 2 min (1 min mean sampling at $1 \mathrm{~Hz}$ ). Directional waves were measured every hour based on 20 min burst sampling at $2 \mathrm{~Hz}$. Data on wind speed and direction (recorded every minute at Onslow airport) were obtained from the Bureau of Meteorology (www.bom. gov.au).

\section{Hatchling capture}

A total of 91 flatback turtle hatchlings were obtained from the south-eastern side of Thevenard Island for use in the tracking study. The beach was monitored at night and in the early hours of the morning for evidence of newly emerged, or the immi-

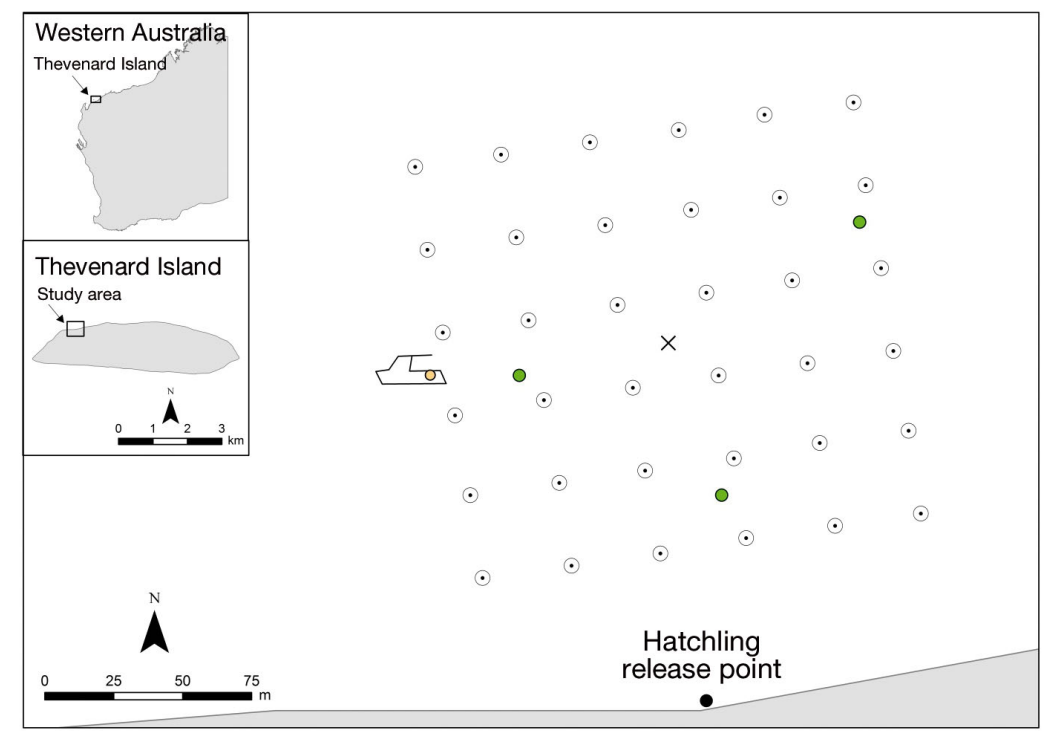

Fig. 1. The acoustic tracking array, with open circles representing receivers (30 $\mathrm{m}$ apart), each with a co-located synctag. The position of the 3 reference tags (to measure system performance) are shown in green circles and the ADCP (to measure current and water parameters) as a black cross. Experimental lights were located on a boat (yellow circle) moored mid-way along the western edge of the array. The beach is shown in grey in the bottom of the plot and the hatchling release point is marked 
nent emergence of, hatchlings. Hatchlings were collected from within or near the nests and were kept in an insulated box with a sand floor in a dark, quiet room until later that night or the following nights and then tagged and released as part of the experiment. Where hatchlings were collected from multiple nests or at different times, they were distributed evenly among experimental treatments. Straight carapace length $(\mathrm{SCL})$ and width $(\mathrm{SCW})( \pm 0.1 \mathrm{~cm})$ and body mass $( \pm 0.1 \mathrm{~g})$ were measured using digital callipers and a digital scale.

\section{Acoustic tags and tag attachment}

Uniquely coded, V5 acoustic transmitters $(180 \mathrm{kHz}$, $0.65 \mathrm{~g}$ in air, $0.38 \mathrm{~g}$ in water, $12.7 \mathrm{~mm}$ long, $4.3 \mathrm{~mm}$ diameter, with a 5 to $10 \mathrm{~s}$ transmission rate) were attached vertically to the underside of hatchlings with the transducer pointing down (Thums et al. 2016) using a small drop of fast-acting epoxy (Selleys Araldite 5 Minute Adhesive). The transmitters weighed $1.95 \%$ (weight in air) of the mean weight $(33.3 \pm$ $2.2 \mathrm{~g}$ ) of hatchlings. Tag diameter was $8.8 \%$ of the average SCW $(49.1 \pm 2.0 \mathrm{~mm})$ and $7.1 \%$ of the average SCL $(60.2 \pm 1.5 \mathrm{~mm})$ and tag length was approximately 30 to $60 \%$ of the depth of a hatchling (depth estimated at 20 to $40 \mathrm{~mm}$ ).

\section{Light experiment}

Experiments were conducted over 3 consecutive nights during the new moon phase, following moon set on 8 February after 21:00 h, beginning on the rising tide and ending on an outgoing tide each night (Table 1). High tide occurred at 23:06 h $(2.49 \mathrm{~m})$, $23: 51 \mathrm{~h}(2.57 \mathrm{~m})$, and 00:31 h $(2.60 \mathrm{~m})$, respectively, over the 3 nights. On each night, we examined hatchling dispersal through the array under ambient conditions and in relation to 2 different types of $400 \mathrm{~W}$ lights; high pressure sodium (HPS) vapour (amber in colour with peak wavelengths at 560 to $600 \mathrm{~nm}$ and wavelength range of 500 to $630 \mathrm{~nm}$ ) and metal halide $\left(\mathrm{MH}_{\text {; }}\right.$ white in colour and enriched in short wavelengths [400 to $500 \mathrm{~nm}$ ] relative to HPS, and emitting light between 500 and $600 \mathrm{~nm}$ ) (Pendoley \& Kamrowski 2015). These light types are commonly used in industrial settings in the region (Pendoley 2005) and represent one of the least and one of the most attractive to flatback hatchlings on land, respectively (Pendoley \& Kamrowski 2015). The lights were positioned on a boat moored at the edge of the western side (selected at random) of the array (Fig. 1), with the light angled slightly downward and facing the beach, creating a light spill near the boat. We attempted to determine whether there was a bias in hatchling bearing during dispersal prior to the experiments by following dispersing hatchlings $(\mathrm{n}=$ 12) during the day with a kayak but no side bias was detected (5 oriented westward, 6 oriented eastward and 1 oriented directly offshore).

Transmitters were glued to the underside of turtles (Table 1) and allowed to cure (10 $\mathrm{min}$ ) before they were released into the array (Fig. 1) either under dark ambient conditions or with artificial lights present. Hatchlings were not given the opportunity to crawl to the water as they could not do so once the

Table 1. Timing of the experiments over the 3 consecutive nights, tidal state, mean \pm SD straight carapace length (SCL), straight carapace width (SCW) and weight of hatchlings tracked in each light treatment (ambient, metal halide [MH], high pressure sodium [HPS]), as well as hatchling collection times and dates. The number of hatchlings tracked per treatment was usually 10 except in the ambient treatment on Night 1 (10 turtles were released but 1 tag had no detections)

\begin{tabular}{|c|c|c|c|c|c|c|c|c|}
\hline Treatment & Start & End & Tide & No. tracked & SCL (mm) & $\mathrm{SCW}(\mathrm{mm})$ & Weight (g) & Collected \\
\hline \multicolumn{9}{|c|}{08 Feb 2016} \\
\hline HPS & $21: 15$ & $22: 50$ & Flood & 10 & $61.5 \pm 1.4$ & $51.2 \pm 2.2$ & $33.0 \pm 2.7$ & 06 Feb 2016 23:00 \\
\hline Ambient & 23:00 & $00: 15$ & Ebb & 9 & $60.1 \pm 0.9$ & $49.7 \pm 1.0$ & $32.7 \pm 2.0$ & 06 Feb 2016 23:00 \\
\hline $\mathrm{MH}$ & $00: 17$ & $01: 30$ & Ebb & 10 & $61.0 \pm 1.5$ & $50.1 \pm 1.2$ & $31.0 \pm 2.4$ & 06 Feb 2016 23:00 \\
\hline \multicolumn{9}{|c|}{09 Feb 2016} \\
\hline Ambient & $21: 13$ & $22: 26$ & Flood & 10 & $60.6 \pm 1.5$ & $49.2 \pm 1.5$ & $34.1 \pm 1.7$ & 08 Feb 2016 07:00 \& 06 Feb 2016 23:00 \\
\hline $\mathrm{MH}$ & $22: 56$ & 00:06 & Ebb & 10 & $60.1 \pm 0.9$ & $48.7 \pm 1.8$ & $33.1 \pm 1.0$ & 08 Feb 2016 07:00 \& 06 Feb 2016 23:00 \\
\hline HPS & $00: 25$ & $01: 35$ & Ebb & 10 & $59.5 \pm 2.0$ & $48.0 \pm 1.8$ & $32.9 \pm 1.6$ & 08 Feb 2016 07:00 \& 06 Feb 2016 23:00 \\
\hline \multicolumn{9}{|c|}{10 Feb 2016} \\
\hline $\mathrm{MH}$ & $22: 30$ & $23: 40$ & Flood & 10 & $59.0 \pm 1.5$ & $47.8 \pm 2.0$ & $33.0 \pm 1.2$ & 09 Feb 2016 22:30 \& 10 Feb 2016 18:00 \\
\hline HPS & $23: 50$ & $01: 15$ & Ebb & 10 & $59.7 \pm 1.3$ & $48.6 \pm 1.7$ & $34.2 \pm 1.7$ & 09 Feb 2016 22:30 \& 10 Feb 2016 18:00 \\
\hline Ambient & $01: 35$ & 03:00 & Ebb & 10 & $60.2 \pm 1.1$ & $48.4 \pm 2.0$ & $36.1 \pm 1.6$ & 09 Feb 2016 22:30 \& 10 Feb 2016 18:00 \\
\hline
\end{tabular}


transmitter was attached. They were carried to the water and held at the water surface for approximately 5 to $10 \mathrm{~s}$ to invoke the swimming response prior to release.

For each light treatment (ambient, HPS and MH), 5 pairs of tagged hatchlings were released every $10 \mathrm{~min}$ into the array and tracked for up to $90 \mathrm{~min}$, giving those hatchlings released at 40 min a maximum time of $50 \mathrm{~min}$ to swim through the array. Green turtle hatchlings have been found to spend approximately $20 \mathrm{~min}$ in the array (Thums et al. 2016), so this was considered sufficient time for all hatchlings to have left the tracking area. The order of the treatments was randomised across the 3 nights to ensure that each treatment occurred during both ebb and flood tide conditions (Table 1). We quantified light in each treatment using a digital all-sky camera (see Fig. S1 and further information in Supplement 1 for details).

\section{Data analysis}

Data from acoustic receivers were downloaded the day after the last experiment and were sent to Vemco for calculation of turtle $x y$ positions as they moved through the array. To determine if lights influenced how long hatchlings spent in the nearshore, we calculated the time spent by each turtle in the array, defined as the time from when each turtle was detected by the receivers in the array until the time it left the array. The $x y$ positions were used to calculate how many hatchlings were attracted to the light, and a number of parameters which were used as response variables (described below) to test for an effect of light treatment. These were mean speed (distance between each calculated position divided by the time difference between the positions), mean bearing (relative to $0^{\circ}$ such that westerly bearings were negative) and variance in bearing (a measure of confusion) for each hatchling from the release point to the point where it left the tracking area. Tracks were also divided into inshore of the light (south of latitude $-21.4516^{\circ}$ ) and at the light location (latitude $<-21.45125^{\circ}$ but $>-21.4516^{\circ}$ ) for the testing of the response variable mean speed to provide more information with which to understand turtle energetic expenditure in relation to light attraction. For the response variable mean bearing, only tracks inshore of the light were used (south of latitude $-21.4516^{\circ}$ ), because the test was designed to test hatchling attraction from shore to the light. Their tracks beyond the light were not needed and, if included, might have confounded the test as, once at the light, hatchlings became confused and moved in tortuous ways. The R (R Core Team 2015) package 'circular' (Lund et al. 2017) was used to calculate mean bearing and circular variance of bearing for each turtle. We also implemented kernel density estimation on all the tracks combined using the bkde2D function in the $\mathrm{R}$ package 'KernSmooth' (Wand 2015) to determine the areas that had the highest density of locations and depict the spatial distribution of the locations. We made a subjective visual choice of the smoothing parameter 'bandwidth' based on successive trials (Silverman 1986, Wand \& Jones 1995).

To determine if the length of holding time prior to releasing hatchlings influenced our results, we tested each response variable with the number of days held (Categorical: 0 [<1 d], $1[1 \mathrm{~d}], 2$ [1.5 to $2 \mathrm{~d}], 3[3 \mathrm{~d}]$ ) using a linear model and compared the Akaike's information criterion, corrected for small sample size $\left(\mathrm{AIC}_{\mathrm{c}}\right)$ and model weights of the slope model (response $\sim$ days held) to the intercept-only model (response $\sim 1$ ).

Wave height, period and direction were measured by the ADCP every 20 min over the study period. For the period of each turtle's transit through the array, we calculated mean wave steepness (wave height/ wave length) and peak wave direction. There were typically 1 or more measurements of wave steepness and direction for each turtle ( $64 \%$ ), and the transit of $36 \%$ of turtles did not correspond to a specific measurement, so the closest measurement in time was used. Mean current speed and direction, calculated at 2 min intervals using the ADCP, and average wind speed and direction (obtained every min) was also determined for each turtle's transit.

\section{Impact of light treatment on hatchling dispersal}

Time spent in the array, mean bearing inshore of the light, variance in bearing, and mean speed were then used as response variables in a suite of generalised additive models (GAMs) to examine the relationship with light treatment (categorical: ambient, HPS, MH), current direction (categorical: flood and ebb tide) and the continuous variables: current speed, wind speed and wave steepness. Predictors with insufficient variation were excluded from modelling and these included water temperature, depth, wind direction and peak wave direction. The gamm4 function in the mgcv library (Wood 2017) in R was used to fit models. We used a function developed by Fisher et al. (2018) to fit all possible combinations of 
the predictor variables and the interactions between the categorical variables and each of the continuous variables, as well as the interaction between the 2 categorical variables. A Pearson's correlation cut-off value of 0.28 (between predictors) was used for excluding models with correlated predictors (Graham 2003). All continuous predictors were modelled as smooths, using a cubic regression spline, with $\mathrm{k}$ restricted to 5 following the default settings of the full subsets GAM function used. Model selection was then achieved by ranking each model using the $\mathrm{AIC}_{\mathrm{C}^{\prime}}$ and their relative model weight, the $\mathrm{AIC}_{\mathrm{C}}$ weight $\left(\mathrm{wAIC}_{\mathrm{c}}\right)$. We also calculated overall variable importance (summed model weights for each predictor).

Time spent in the array was rounded to the nearest minute and then modelled as a binomial distribution with 50 trials, representing the maximum of $50 \mathrm{~min}$ in the array. Each individual turtle (turtle ID) was included as a random effect. Mean bearing inshore of light and mean speed were modelled with a Gaussian distribution as these variables adequately fit a normal distribution. Variance in bearing was modelled using a gamma distribution.

For all models, night was included as a random effect to account for non-independence of observations across the sampling nights.

The mean centroid track $\left(x_{0}(t), y_{0}(t)\right)$ for a group of hatchlings for each treatment on both the flood and ebb tides was calculated (Johnson \& Pattiaratchi 2004):

$$
x_{0}(t)=\frac{1}{n} \sum_{i=1}^{n} x_{i}(t) \quad y_{0}(t)=\frac{1}{n} \sum_{i=1}^{n} y_{i}(t)
$$

where $\mathrm{x}_{i}, \mathrm{y}_{i}$ was the position of one of $n$ positions of a group of hatchlings in a treatment. A mean latitude and longitude position for each turtle was calculated at $1 \mathrm{~min}$ intervals for the length of its track. Each position was allocated a time bin, and for time bins 1 to 10 , a mean latitude and longitude of hatchlings was calculated from all turtles in that treatment, on the flood or ebb tide. This allowed us to determine the centroids for groups of hatchlings in different treatments and under different tidal conditions. This was calculated for the first $10 \mathrm{~min}$, as after this time, there were not always 3 or more turtles available in each group to calculate a mean.

\section{Natural predictors of hatchling dispersal}

To determine how oceanographic conditions influence hatchling trajectories under natural conditions, the mean bearings of entire tracks from the ambient treatment (modelled with a Gaussian distribution) were used to test for an effect of environmental predictors using a similar statistical procedure (full subsets modelling [Fisher et al. 2018] ranked according to $\mathrm{AIC}_{\mathrm{C}}$ ). Predictors included the factors current direction and wave steepness, and the continuous variables current speed and wind speed, again with night as a random effect in all models. Wave steepness was converted to a factor in this analysis as only small and larger values were present in this treatment, and were thus unable to be fit well using cubic splines. All other predictors were excluded as they did not change over the study period.

Positions were corrected for current displacement (Gaspar et al. 2006) to qualitatively examine the dispersal of hatchlings in relation to wave direction. For each animal position, current speed and direction was determined using the closest value to the time and date of that position $(<2 \mathrm{~min})$. The speed and direction of the turtle was calculated by determining the distance and bearing between 2 spatial points, and then calculating the rate of travel based on the distance and the time taken between them using $\mathrm{R}$ packages 'sp' (Pebesma et al. 2017) and 'geosphere' (Hijmans et al. 2016). For each position, the speed and direction of the turtle and of the currents was used to calculate $U$ (east/west) and $V$ (north/south) components for the turtle $\left(U_{\mathrm{t}}, V_{\mathrm{t}}\right)$ and for the current $\left(U_{\mathrm{c}}, V_{\mathrm{c}}\right)$ which were subsequently used to calculate the current corrected speed and direction (Table S1). A mean centroid track (current corrected track) on both the flood and ebb tides was determined using the methods described above and the mean current corrected speed was calculated.

\section{RESULTS}

\section{Acoustic array performance}

Hatchlings measured on average (mean \pm SD) 60.2 $\pm 1.5 \mathrm{~mm}$ SCL and $49.1 \pm 2.0 \mathrm{~mm} \mathrm{SCW}$, and weighed $33.3 \pm 2.2 \mathrm{~g}$ (Table 1). Hatchlings collected on 6 and 8 February were all collected from 1 nest each night, whereas hatchlings collected on 9 and 10 February were from multiple nests and were divided evenly among treatments. Total detections ranged from 10 to 2705 per individual. From these detections, 2268 positions were calculated for 89 individual animals, ranging from 1 to 127 positions. One animal was released but no detections were determined and another animal was detected 15 times but no positions were determined (i.e. detections were not re- 
corded on 3 or more receivers at the same time). Three animals were excluded from the analysis of time spent in the array as they were detected over multiple days (2646, 2705 and 2335 detections for each tag, respectively). On closer inspection, these detections were predominantly recorded by 1 receiver, suggesting that the tag had detached, perhaps during a predation event. Positions prior to tag detachment were included in all other analyses. Another 4 animals had less than 3 calculated positions or high error around their positions and were excluded from the analysis of bearing and speed. This resulted in data from 87 animals (26 ambient, $31 \mathrm{HPS}, 30 \mathrm{MH}$ ) analysed for time spent in the array, and data from 85 animals (29 ambient, $27 \mathrm{HPS}$, $29 \mathrm{MH}$ ) used in the analyses of turtle bearing, speed and mean tracks. The 29 turtles dispersing under ambient conditions were used in the analysis of the mean bearing and of these, 26 had sufficient position estimates (>3 points) for current correction of tracks.

There was no evidence for a difference in hatchling speed, variance in bearing or time spent in the array with number of days held prior to release, with the null model having the highest support $\left(\mathrm{wAIC}_{\mathrm{C}}=0.89\right.$, $0.76,0.76$, respectively). For bearing inshore of light, the slope model and the null model were both within 2 AICc points, thus the null model was the most parsimonious.

\section{Environmental conditions}

Median current velocity was $0.14 \mathrm{~m} \mathrm{~s}^{-1}$, ranging from 0.01 to $0.30 \mathrm{~m} \mathrm{~s}^{-1}$. Currents were driven by tidal movement and ran in an ENE direction on the flood tide (median speed $0.07 \mathrm{~m} \mathrm{~s}^{-1}$ ) and a WSW direction on the ebb tide (median speed $0.17 \mathrm{~m} \mathrm{~s}^{-1}$ ) (Fig. S2 in Supplement 1). Median significant wave height was $0.21 \mathrm{~m}$, ranging between 0.04 and $0.26 \mathrm{~m}$. Sea waves approached from a WNW direction and swell waves from a NNW direction, with peak wave direction coming from the NW each night (Fig. S2). Wind speed ranged from 0 to $5 \mathrm{~m} \mathrm{~s}^{-1}$, mean of $3.06 \mathrm{~m} \mathrm{~s}^{-1}$, and consistently approached from a westerly direction (Fig. S2). Water depth varied from 1.3 to $2.4 \mathrm{~m}$, with a median depth of $2.2 \mathrm{~m}$ during the experiment (Fig. S3). Wave period was largely dominated by shorter periods (wave period $<6 \mathrm{~s}$ ), with the exception of Night 3 during the ambient treatment, when winds dropped off and longer swell-generated periods dominated (wave period $>8 \mathrm{~s}$ ). Water temperature ranged from 28.7 to $30.8^{\circ} \mathrm{C}$, but was mainly around $30^{\circ} \mathrm{C}$ with the exception of a $1.3^{\circ} \mathrm{C}$ drop (cold front) which coincided with the tidal movement (Fig. S3).

\section{Impact of light on hatchling dispersal}

\author{
Hatchling attraction to lights and \\ time spent in array
}

More hatchlings were attracted to the $\mathrm{MH}$ light (80\%) than the HPS light (63\%) (Fig. 2b,c, Video S1 $\& \mathrm{~S} 2$, respectively at www.int-res.com/articles/suppl/ m600p179_supp/). Under ambient conditions, 72\% of hatchling tracks fanned out in a westerly direction, while $28 \%$ aligned more in a northerly direction through the middle of the array (Fig. 2a,d, Video S3), whereas in the light treatments, hatchling tracks were more directed to and concentrated around the light source located northwest of the release location. In the $\mathrm{MH}$ treatment, 80 to $90 \%$ of hatchlings went to or towards the light, whereas $3 \%$ oriented to the north through the array and $7 \%$ went to the west of the light (Fig. 2c,f). In the HPS treatment, 63\% of hatchling tracks went to the light, $27 \%$ went towards the west, left of the light, $7 \%$ went in a northerly direction through the middle of the array and the remaining $3 \%$ did not have enough positions to confirm direction (Fig. 2b,e). All of the hatchlings that oriented northwards through the middle of the array were tracked on the flood tide when currents ran towards the east.

When considering the analysis done on data from the entire tracking area, and the response variables time spent in the tracking area, rate of travel, and variance in bearing, the top ranked model included light treatment only $\left(\mathrm{wAIC}_{\mathrm{c}}=0.49,0.88\right.$ and 0.55 , respectively), with light treatment explaining 17, 29, and $23 \%$ of the deviance (Table S2). In ambient conditions, turtles spent $9.6 \mathrm{~min}$ (95\% CI: 6.1-14.5) in the tracking area, remaining in the area $50 \%$ longer when HPS light was present (14.4 min; 95\% CI: 9.8-20.1) and $150 \%$ longer when $\mathrm{MH}$ light was present (24.0 min; $95 \%$ CI: 17.7-30.3) (Fig. 3a). Two individual hatchlings became noticeably trapped in the light spill of the $\mathrm{MH}$ light for approximately $1 \mathrm{~h}$ and did not move on until the light was switched off. This trapping effect did not occur with the HPS light. There was weak (24\%) support for a model that included an additive effect of wave steepness, suggesting that hatchlings spent less time in the array when waves were steeper (higher wave height and shorter wave period). Turtles moved offshore faster when light was absent $\left(0.50 \mathrm{~m} \mathrm{~s}^{-1} ; 95 \% \mathrm{CI}\right.$ : $0.46-$ 

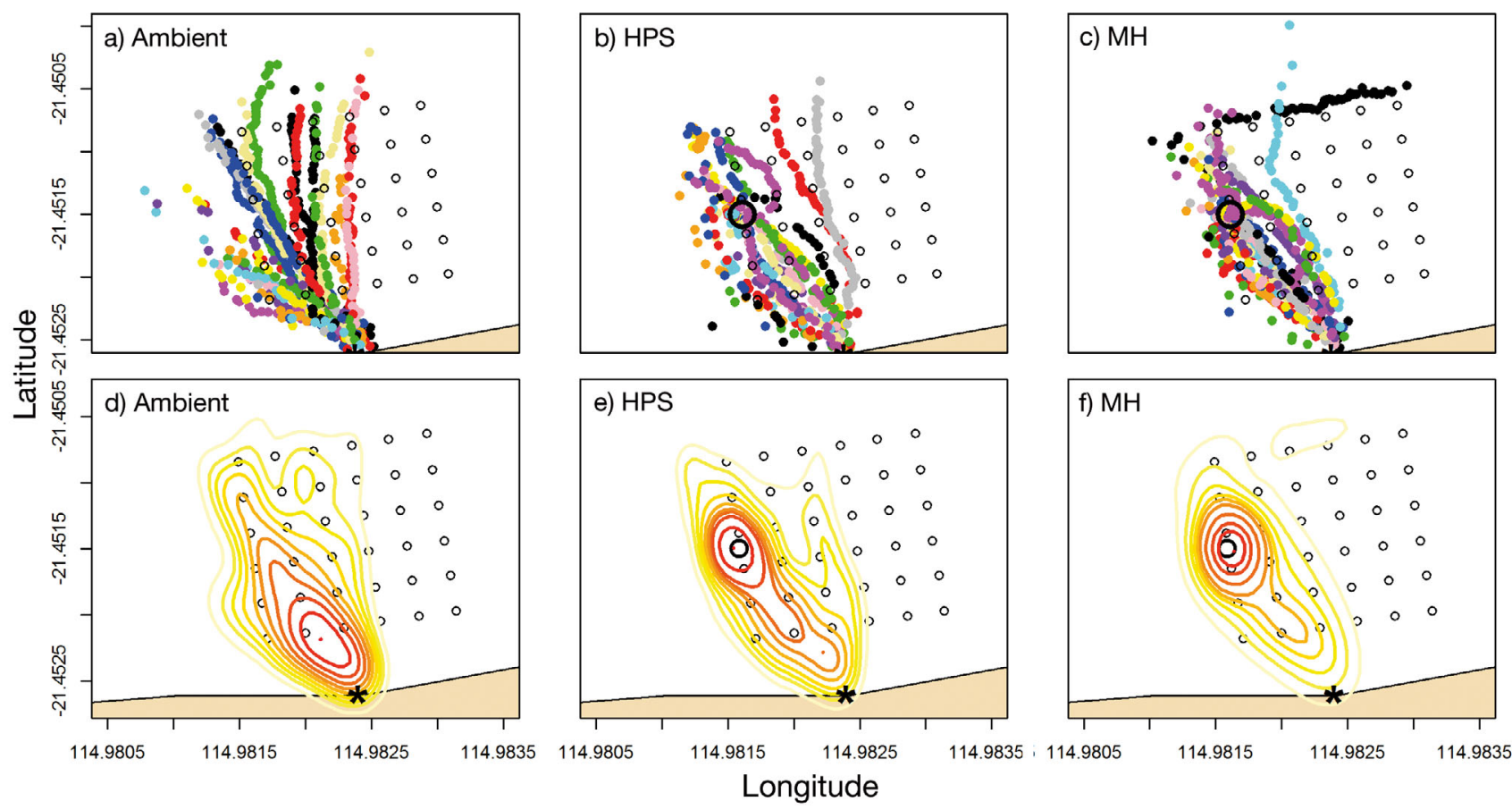

Fig. 2. (a-c) Tracks of individual hatchlings represented by different colours and (d-f) kernel density plots of hatchling positions from 89 individuals in $(\mathrm{a}, \mathrm{d})$ ambient, $(\mathrm{b}, \mathrm{e})$ high pressure sodium (HPS) and (c, f) metal halide (MH) treatments. The light was located on a boat (larger black circle) moored midway along the western edge of the array $\left(21.4514^{\circ} \mathrm{S}, 114.98159^{\circ} \mathrm{E}\right)$. Open circles: acoustic receivers; black star: hatchling release point $\left(21.4526^{\circ} \mathrm{S}, 114.9824^{\circ} \mathrm{E}\right)$. The beach is in beige at the bottom of each plot. Warmer colours in $(\mathrm{d}-\mathrm{f})$ correspond to higher density of turtle locations
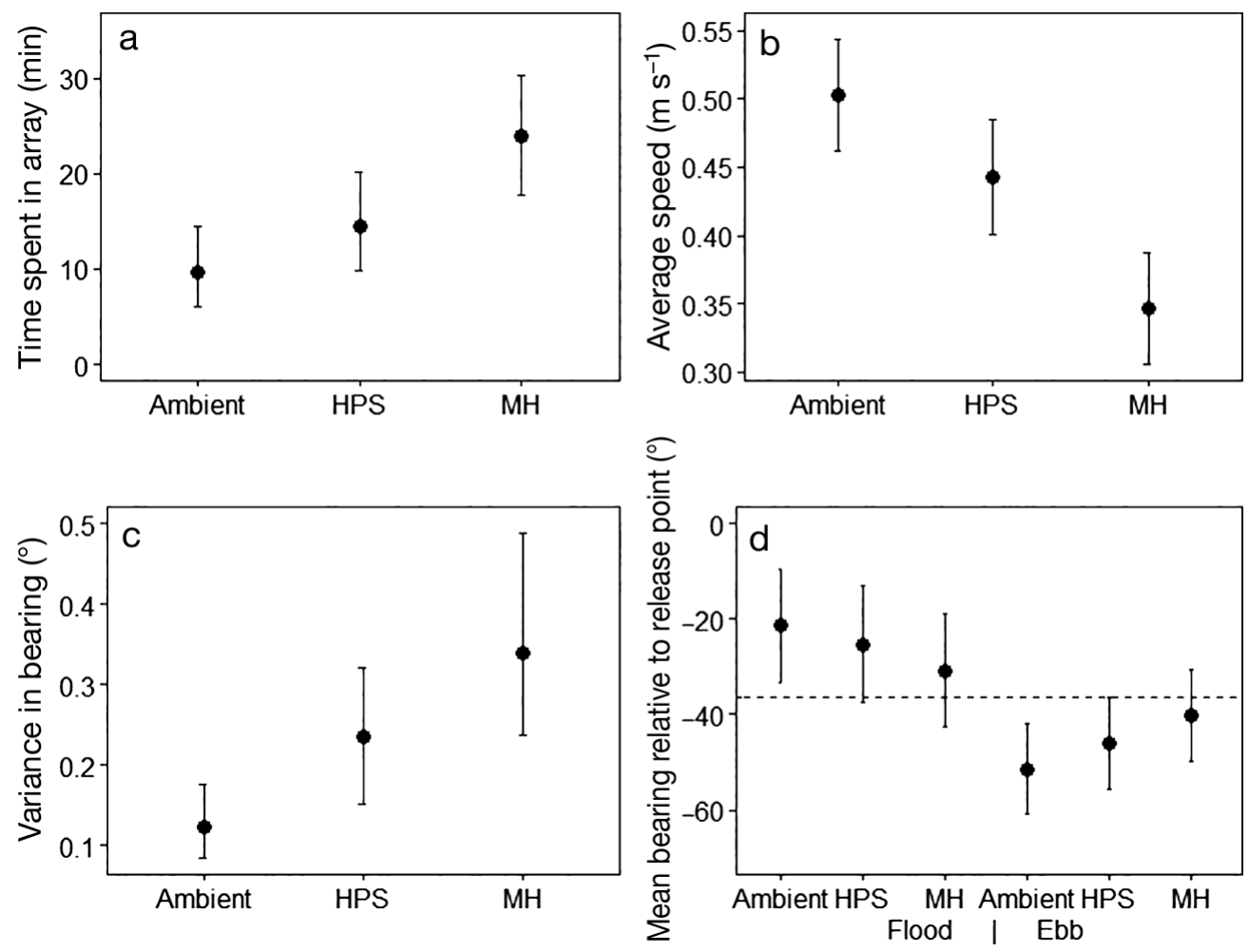

Fig. 3. Estimated values (mean $\pm 95 \% \mathrm{CI}$ ) from the top-ranked model (light treatment effect or interaction between light treatment and tidal state) for (a) the time that turtle hatchlings spent in the tracking array, (b) hatchling rate of travel, (c) variance in bearing and (d) mean turtle bearing inshore of light. The experimental light (metal halide $[\mathrm{MH}]$ and high pressure sodium [HPS]) was located at a mean bearing of $-36.5^{\circ}$ (black dashed line) from the hatchling release point 
0.54) than when light was present, with the $\mathrm{MH}$ light producing the slowest rate of travel $\left(0.44 \mathrm{~m} \mathrm{~s}^{-1} \mathrm{HPS}\right.$;

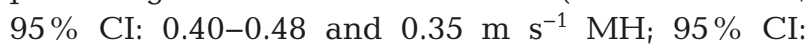
0.31-0.39) (Fig. 3b). Variance in turtle bearing (a measure of disorientation) increased from 0.12 (95\% CI: 0.08-0.17) under ambient conditions to 0.24 (95\% CI: 0.15-0.32) for the HPS light treatment, with a further increase to 0.34 (95\% CI: 0.24-0.49) for the $\mathrm{MH}$ light treatment (Fig. 3c).

When modelling mean speed using the data inshore of the light and near the light, light treatment was the top ranked model near the light and current speed was the top model inshore of the light, having wAIC $_{\mathrm{c}}$ values of 0.99 and 0.87 , respectively, and explaining 28 and $59 \%$ of the deviance (Fig. S4, Table S2). Inshore of the light, hatchling swim speed increased with current speed (Fig. S4a), but not in relation to light treatment. However, near the light turtles moved faster under ambient conditions (0.50 $\left.\mathrm{m} \mathrm{s}^{-1} ; 95 \% \mathrm{CI}: 0.44-0.56\right)$ than when light was present $\left(0.25 \mathrm{~m} \mathrm{~s}^{-1}\right.$ in HPS treatment; $95 \% \mathrm{CI}$ : $0.19-$ 0.3 and $0.23 \mathrm{~m} \mathrm{~s}^{-1}$ in $\mathrm{MH}$ treatment; $95 \% \mathrm{CI}$ : $0.17-$ 0.28) (Fig. S4b). These tests suggest that the reduction in swim speed with light treatment that we observed using the full tracks is not a result of the turtles swimming faster to get to the light, but is from lingering around the light source.

\section{Hatchling bearing}

There was strong evidence $\left(\mathrm{wAIC}_{\mathrm{C}}=1\right.$ ) for a 2-way interaction effect between current direction and treatment on the mean bearing that hatchlings took relative to the release point $\left(0^{\circ}\right.$ directly north such that westerly bearings were negative), with this model explaining $38 \%$ of the deviance (Table S2). The experimental light was located at a mean bearing of $-36.5^{\circ}$ from the hatchling release point over the 3 nights (black dashed line, Fig. 3d). Ocean currents flowed parallel to shore and to the east during the flood tide and more strongly to the west during the ebb tide. Tidal flow had the greatest influence on hatchling bearing in the ambient treatment, with a $30^{\circ}$ difference in turtle bearing depending on current direction (flood tide $-21.3^{\circ} ; 95 \% \mathrm{CI}:-33.2^{\circ}$ to $-9.4^{\circ}$, ebb tide $-51.4^{\circ} ; 95 \% \mathrm{CI}:-60.9^{\circ}$ to $-41.9^{\circ}$ ) (Fig. 3d). Currents had a smaller effect on mean bearing when light was present, $21^{\circ}$ in HPS (flood tide $-25.3^{\circ} ; 95 \%$ CI: $-37.4^{\circ}$ to $-13.1^{\circ}$, ebb tide $-46.2^{\circ} ; 95 \% \mathrm{CI}:-55.8^{\circ}$ to $-36.6^{\circ}$ ) and $9^{\circ}$ in $\mathrm{MH}$ treatments (flood tide $-30.8^{\circ}$; $95 \% \mathrm{CI}:-42.6^{\circ}$ to $-18.9^{\circ}$, ebb tide $-40.2^{\circ}$; $95 \% \mathrm{CI}$ : $-49.7^{\circ}$ to $-30.7^{\circ}$ ) (Fig. 3d). This suggests that turtles in the light treatments actively swam against currents and towards the light, whereas in the ambient treatment their movements were more influenced by currents.

\section{Mean centroid track}

The mean track analysis showed that the effect of tides on the movement of hatchlings was reduced when light was added, particularly in the vicinity of the light (Fig. 4). Hatchlings moved towards the north on the flood tide and towards the northwest on the ebb tide in ambient treatments (Fig. 4a). However, when artificial light was present, it appeared to
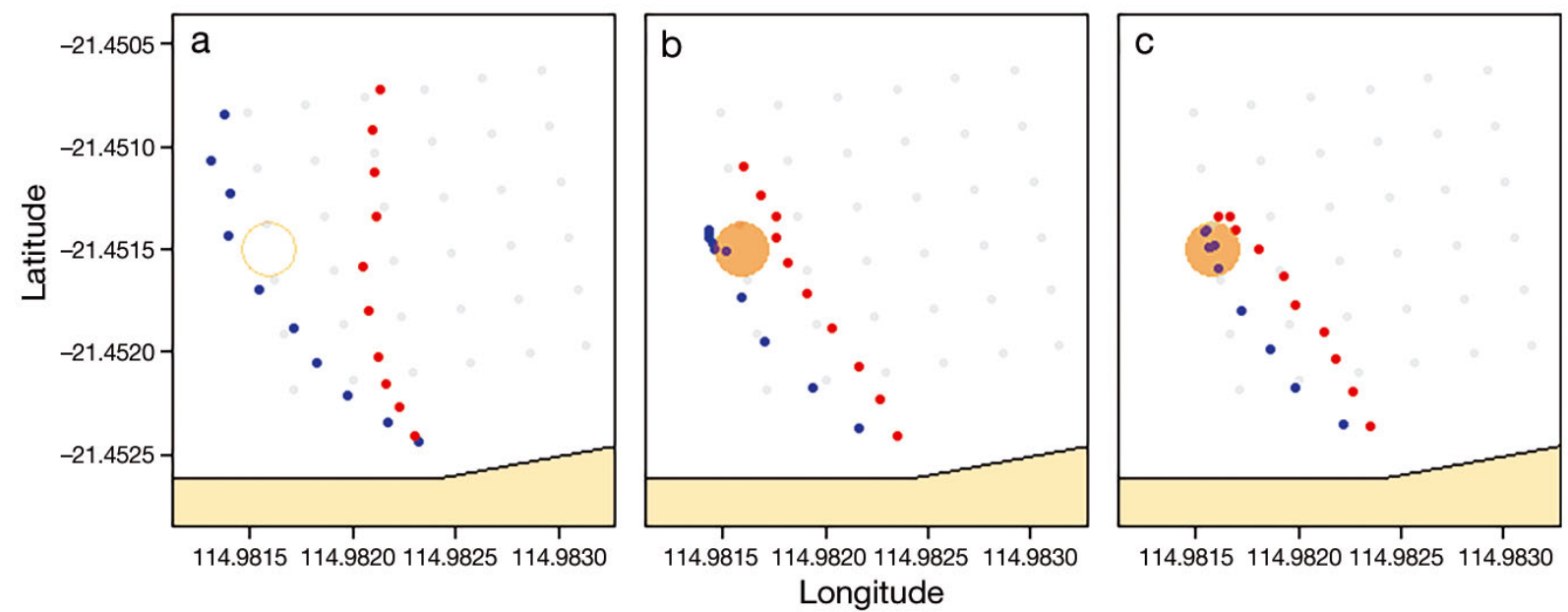

Fig. 4. Mean track taken by hatchlings in (a) ambient, (b) high pressure sodium and (c) metal halide treatments on flood (red) and ebb (blue) tides. Orange circle: location of the light spill; grey circles: acoustic receivers. Note that an outline of the light spill is present in the ambient treatment for reference only. The beach is in beige at the bottom of each plot 
largely override this effect (Fig. 4b,c), with hatchlings moving in a similar direction towards the light and the difference between mean tracks on the different tides was reduced, most notably in the $\mathrm{MH}$ treatment (Fig. 4c). Some of the hatchlings managed to stay at the light for up to $1 \mathrm{~h}$, showing an ability to swim against currents of up to $0.3 \mathrm{~m} \mathrm{~s}^{-1}$ (maximum current speed recorded during the study).

\section{Natural predictors of hatchling dispersal}

Mean hatchling bearing under ambient conditions of tracks through the entire array was best explained by current direction, with $62 \%$ support for this model $\left(\right.$ wAIC $_{\mathrm{c}} 0.62 \%$ ), which explained $48 \%$ of the deviance (Table S2). There was a $40^{\circ}$ difference in turtle bearing depending on the current direction (mean bearing on flood tide [eastward flow] was $-12.1^{\circ}$; $95 \% \mathrm{CI}$ : $-35.4^{\circ}$ to $11.2^{\circ}$, and mean bearing on ebb tide [westward flow] was $-51.7^{\circ} ; 95 \% \mathrm{CI}:-68.4^{\circ}$ to $-35.1^{\circ}$ ). The influence of tides on hatchling bearing, relative to their release point, increased with distance from shore. When hatchlings were inshore of the light there was a $30^{\circ}$ difference in bearing, and this increased to $40^{\circ}$ by the time they reached the furthest edge of the array. Wave steepness was the next most important variable influencing hatchling bearing.

Hatchling tracks for the entire array were current corrected (Fig. S5a,b). The mean track analysis of current-corrected tracks showed that turtles moved perpendicular to the shoreline when the current drift was subtracted from their positions (Fig. S5c). They did not appear to orient into the peak wave direction that approached from the northwest (black arrow, Fig. S5c). These waves were mostly short period $(<6 \mathrm{~s})$ waves generated from local winds. There was a small change in mean trajectory on the flood tide after correcting for currents, as current speeds were weak (Figs. 4a \& S5c). However, there was a large change on the ebb tide, driven by the stronger currents on the outgoing tide (Figs. 4a \& S5c). Mean currentcorrected speed was $0.47 \mathrm{~m} \mathrm{~s}^{-1}$, ranging from 0.35 to $0.62 \mathrm{~m} \mathrm{~s}^{-1}$. Although current corrections were not applied to hatchlings in light treatments, Fig. S5d illustrates the ability of hatchlings to stay at the light spill despite increasing current speeds.

\section{DISCUSSION}

Our acoustic tracking, combined with fine-scale measurements of oceanography and experimental manipulations of light, allowed us to identify the relative importance of both natural and artificial cues to the nearshore dispersal of hatchling flatback turtles. Artificial light was a strong predictor of the in-water movement behaviour of flatback turtle hatchlings, largely overriding the influence of oceanographic cues and likely incurring energetic costs and increasing predation risk. Similar to studies of the effect of light pollution on the dispersal of turtles from beach nests to the seashore (Witherington \& Bjorndal 1991, Pendoley 2005, Fritsches 2012, Pendoley \& Kamrowski 2015), artificial light enriched in short wavelengths such as the MH light had a more disruptive effect on in-water movement of hatchlings than light enriched in longer wavelengths (e.g. HPS light), but both types elicited behavioural responses above that of ambient light. In the absence of artificial light, ocean currents had a strong influence on the path taken by hatchlings moving offshore, and once their tracks had been corrected for current drift, they did not appear to respond to wave direction as a navigational cue, moving mostly perpendicular to the coastline after release.

The $\mathrm{MH}$ light was more attractive to hatchlings than the HPS light ( $80 \%$ attracted) and had the largest impact on the time they spent crossing the nearshore zone (150\% greater than ambient). However, HPS lighting still had a substantial effect on hatchling behaviour $(63 \%$ attracted, and $50 \%$ more time spent crossing the nearshore zone than ambient), despite it being recommended as the best available light option for use in turtle rookery areas (Pendoley \& Kamrowski 2015). Although HPS lighting is enriched in long wavelength light (>550 nm), it still emits a small amount of short wavelength light, especially at $500 \mathrm{~nm}$, which renders it attractive to turtle hatchlings (Witherington \& Bjorndal 1991, Pendoley 2005). While it is clearly a better option than $M H$, the effect size we recorded indicates that lighting recommendations at turtle rookeries may need to be more extensive, perhaps including the use of light shields (Pendoley \& Kamrowski 2016), embedding lighting into jetties or structures (Bertolotti \& Salmon 2005), or reducing the number of lights or light intensity (Gaston et al. 2012). Red light or task lighting might be further options to be considered.

Importantly, we found that the MH light could have a 'trapping effect' (Verheijen 1960) on hatchlings, with some only dispersing once the light was extinguished. In places where lights are illuminated for long periods of the night, entrapment in light spills might result in exhaustion and ultimately, elevated mortality of hatchlings. Furthermore, hatchlings lin- 
gering around lights are likely to become easy prey for sharks and large fish in the nearshore zone (Limpus et al. 2003), so entrapment is also likely to increase the chances of predation. An earlier study found that green turtles Chelonia mydas were also attracted to artificial light at sea, but, unlike flatbacks, they moved through the light spill reasonably quickly, spending about $20 \%$ longer in the tracking area when light was present than during conditions of natural light (Thums et al. 2016). This suggests that some species may be more susceptible to entrapment within artificial light spills than others.

Flatback hatchlings travelled at a mean speed of $0.50 \mathrm{~m} \mathrm{~s}^{-1}$ (95\% CI: $\left.0.46-0.54\right)$ under conditions of natural light. This is similar to the speeds of $0.49 \pm$ $0.08 \mathrm{~m} \mathrm{~s}^{-1}$ reported for green turtle hatchlings (Thums et al. 2016) but higher than speeds reported for this species by an earlier study $(0.34 \pm 0.13$ and $0.25 \pm 0.14 \mathrm{~m} \mathrm{~s}^{-1}$ ) (Thums et al. 2013), although these latter results were obtained from a small sample size of 2 individuals that were actively tracked. In our study, hatchlings travelled 12 to $30 \%$ slower in the artificial light treatments than under ambient conditions, but this was largely due to very slow movement (50 to $55 \%$ slower) through the light spill. Swim speed prior to, and after, passage through the light spill was similar to that of hatchlings released under ambient conditions $\left(0.50 \mathrm{~m} \mathrm{~s}^{-1}\right)$. In contrast, green turtle hatchlings did not alter speed in response to artificial light from a $\mathrm{MH}$ source, largely because they spent less time lingering around the light spill (Thums et al. 2016).

We found that artificial light was not a strong predictor of the bearing of hatchling tracks. This outcome was likely biased by the fact that the light source was positioned on the side of the array that generally corresponded to the direction that the hatchlings took under ambient conditions, which was largely a result of releasing the majority (two-thirds) of the hatchlings on the ebb tide (westward flowing) which carried hatchlings to the west. Although the experimental plan was to release equal numbers of hatchlings on both flood and ebb tide, the study timing was dictated by moon phase and logistics (i.e. moon set occurring at $\sim 20: 20 \mathrm{~h}$ each night and the time needed to deploy and moor the boat on site each night). While recognising these limitations, the study did still find clear differences in time spent, rate of travel and variability in bearing when light was present.

The study confirmed that tidal movement had a substantial influence on the bearing of hatchling movements released under natural conditions (i.e. no artificial light) and that this effect increased as hatchlings moved further offshore. Close to shore (up to $100 \mathrm{~m}$ ) there was a $30^{\circ}$ difference in the direction hatchlings dispersed depending on the tide state. As they moved further away from shore (100 to $250 \mathrm{~m}$ ), this difference increased to $40^{\circ}$. The ratio of mean hatchling speed $\left(0.50 \mathrm{~m} \mathrm{~s}^{-1}\right)$ to maximum current speed $\left(0.3 \mathrm{~m} \mathrm{~s}^{-1}\right)$ was 1.6 , meaning that at this flow and swimming speed, hatchlings could move in any direction as their speed was greater than the speed of the currents (Chapman et al. 2011). Despite this ability to actively select a direction, the increasing displacement of the tracks with increasing distance from shore suggests the hatchlings did not completely compensate for the current advection. This indicates that hatchlings were actively swimming in a constant heading offshore using a strategy known as 'full drift', where the animal maintains its constant heading regardless of the direction of flow (Chapman et al. 2011). Directional swimming such as we observed in the nearshore zone has been suggested to be a strategy that helps flatback hatchlings remain in coastal waters, as it prevents them from being carried out to sea (Wildermann et al. 2017). The nearshore dispersal pathways of turtle hatchlings are largely unknown and are therefore predicted using models (Hamann et al. 2011, Wildermann et al. 2017). Our data on the effect of currents on the displacement of hatchlings, and on the ability of hatchlings to swim against low velocity (up to $0.3 \mathrm{~m} \mathrm{~s}^{-1}$ ) currents to stay at, or move towards artificial lights, will therefore be important in improving these model outcomes through nearshore waters.

Wave direction was not included in the modelling as it consistently came from the northwest, which was a similar bearing to the light source, and both the light position and wave direction remained consistent over the 3 nights. Consequently, we were unable to disentangle the relative importance of these 2 cues to hatchling movement. However, given that hatchlings spent more time in the nearshore zone when light was present despite the presence of waves, it suggests that artificial light is the stronger of the 2 cues. This idea is supported by the work of Thums et al. (2016), who found that green turtle hatchlings responded to light cues irrespective of wave direction, but this was based only on observational data of waves as opposed to quantitative measurements. We did find weak support for an effect of wave steepness in our models, suggesting that the presence of steeper waves which had shorter wave periods and higher heights helped reduce the time spent in the nearshore zone. 
Initially, wave direction appeared important for hatchlings moving offshore on the ebb tide in ambient treatments; however, when tracks were plotted on the different tides, it became evident that this was largely due to the effect of currents on hatchling bearings. When drift due to currents was excluded from tracks, hatchling trajectories moved perpendicular to the shoreline, taking a direct route offshore and not moving to the northwest into approaching waves. Flatback turtles nest on sheltered, low energy beaches (Pendoley et al. 2014) where surface waves are largely generated by local winds. It may be that this species does not respond to wind-generated waves (i.e. wave period $<6 \mathrm{~s}$ ) or that they may be less sensitive to wave cues than other species. This is consistent with the findings from other studies, where hatchlings moved mostly directly offshore (Frick 1976, Ireland et al. 1978). This highlights the importance of taking into account the effects of ocean currents when trying to interpret marine animal dispersal behaviour (Gaspar et al. 2006).

\section{CONCLUSION}

We have shown that ocean currents affect the dispersal pathways of turtle hatchlings, but at least for flatback turtles, orientation appears unlikely to be governed by wave direction. Comparative studies on multiple species moving under natural conditions in relation to wave direction will be valuable in a search for a general consensus on the use of waves as an early offshore navigational cue for this species.

Our study confirmed that artificial light was a cue used by hatchlings orienting in nearshore waters and that it can override other dispersal cues, causing misorientation and increasing the time spent in the nearshore area. Given that predation rates on hatchlings are high in this nearshore zone (Gyuris 1994, Pilcher et al. 2000), light pollution is a key threat to hatchlings dispersing from urbanised and industrial coasts. While longer wavelengths lessened the influence of artificial light in comparison to short wavelength light, behavioural changes were still evident that could delay hatchling transit through the inshore zone. Although light mitigation is commonly used to address impacts on hatchlings on land, our results show that similar light mitigation strategies are needed to minimise impacts on hatchlings in water in the vicinity of structures such as jetties, wharfs, anchored vessels, oil rigs, dredge equipment and landbased infrastructure.
Acknowledgements. Special thanks to the staff of Mackerel Island, Dennis Stanley and Dr Suzanne Long for their assistance in field experiments and to Dr Vinay Udyawer for providing $\mathrm{R}$ code for track animations. The Department of Biodiversity, Conservation and Attractions (formerly Department of Parks and Wildlife), the Australian Institute of Marine Science and the University of Western Australia provided financial support. All procedures were approved by the University of Western Australia Animal Ethics Committee (RA/3/100/1423) and Department of Biodiversity, Conservation and Attractions licenses SF010696.

\section{LITERATURE CITED}

Abe O, Takada Y, Shibuno T, Hashimoto K, Ishii H, Funakura Y (2000) Swimming behaviour of green turtle hatchlings in a lagoon of Ishigaki Island, southwestern Japan. In: Pilcher N, Ismail G (eds) Sea turtles of the Indo-Pacific: research management and conservation. ASEAN Academic Press, London, p 167-175

Avens L, Lohmann KJ (2003) Use of multiple orientation cues by juvenile loggerhead sea turtles Caretta caretta. J Exp Biol 206:4317-4325

* Bertolotti L, Salmon M (2005) Do embedded roadway lights protect sea turtles? Environ Manage 36:702-710

* Chapman JW, Klaassen RHG, Drake VA, Fossette S and others (2011) Animal orientation strategies for movement in flows. Curr Biol 21:R861-R870

Clobert J, Baguette M, Benton TG (2012) Dispersal ecology and evolution. Oxford University Press, Oxford

Daniel RS, Smith KU (1947) The migration of newly-hatched loggerhead turtles towards the sea. Science 106:398-399

Dingle H (1996) Migration: the biology of life on the move. Oxford University Press, New York, NY

Ehrenfeld DW, Carr A (1967) The role of vision in the seafinding orientation of the green turtle (Chelonia mydas). Anim Behav 15:25-36

Fisher R, Wilson SK, Sin TM, Lee AC, Langlois TJ (2018) A simple function for full subsets multiple regression in ecology with R. Ecol Evol 8:6104-6113

Frick J (1976) Orientation and behaviour of hatchling green turtles (Chelonia mydas) in the sea. Anim Behav 24: 849-857

*Fritsches KA (2012) Australian loggerhead sea turtle hatchlings do not avoid yellow. Mar Freshwat Behav Physiol 45:79-89

*Gaspar P, Georges JY, Fossette S, Lenoble A, Ferraroli S, Le Maho Y (2006) Marine animal behaviour: neglecting ocean currents can lead us up the wrong track. Proc R Soc B 273:2697-2702

Gaston KJ, Davies TW, Bennie J, Hopkins J (2012) Reducing the ecological consequences of night-time light pollution: options and developments. J Appl Ecol 49: 1256-1266

Graham MH (2003) Confronting multicollinearity in ecological multiple regression. Ecology 84:2809-2815

Gyuris E (1994) The rate of predation by fishes on hatchlings of the green turtle (Chelonia mydas). Coral Reefs 13: 137-144

*Hamann M, Grech A, Wolanski E, Lambrechts J (2011) Modelling the fate of marine turtle hatchlings. Ecol Modell 222:1515-1521

Harewood A, Horrocks J (2008) Impacts of coastal development on hawksbill hatchling survival and swimming suc- 
cess during the initial offshore migration. Biol Conserv 141:394-401

Hays GC, Fossette S, Katselidis KA, Mariani P, Schofield G (2010) Ontogenetic development of migration: Lagrangian drift trajectories suggest a new paradigm for sea turtles. J R Soc Interface 7:1319-1327

*Hays GC, Ferreira LC, Sequeira AMM, Meekan MG and others (2016) Key questions in marine megafauna movement ecology. Trends Ecol Evol 31:463-475

Hendrickson JR (1958) The green sea turtle, Chelonia mydas (Linn.) in Malaya and Sarawak. Proc Zool Soc Lond 130:455-535

Hijmans R, Williams E, Vennes C (2016) geosphere: spherical trigonometry. R Package Version 1.5-5. https://cran. r-project.org/web/packages/geosphere/index.html

Ireland LC, Frick JA, Wingate DB (1978) Nighttime orientation of hatchling green turtles (Chelonia mydas) in the open ocean. In: Schmidt-Koenig K, Keeton WT (eds) Animal migration, navigation and homing. Springer-Verlag, Berlin, p 420-429

Johnson D, Pattiaratchi C (2004) Transient rip currents and nearshore circulation on a swell-dominated beach. J Geophys Res 109:C02026

Kamrowski RL, Limpus C, Moloney J, Hamann M (2012) Coastal light pollution and marine turtles: assessing the magnitude of the problem. Endang Species Res 19:85-98

Kamrowski RL, Limpus C, Pendoley K, Hamann M (2014a) Influence of industrial light pollution on the sea-finding behaviour of flatback turtle hatchlings. Wildl Res 41: 421-434

Kamrowski RL, Limpus C, Jones R, Anderson S, Hamann M (2014b) Temporal changes in artificial light exposure of marine turtle nesting areas. Glob Chang Biol 20: 2437-2449

Limpus CJ (2007) A biological review of Australian marine turtle species. 5. Flatback turtle Natator depressus (Garman). Environmental Protection Agency, Brisbane

Limpus CJ, Kamrowski RL (2013) Ocean-finding in marine turtles: the importance of low horizon elevation as an orientation cue. Behaviour 150:863-893

Limpus CJ, Miller JD, Parmenter CJ, Limpus DJ (2003) The green turtle, Chelonia mydas, population of Raine Island and the northern Great Barrier Reef: 1843-2001. Mem Queensl Mus 49:349-440

Lohmann KJ, Lohmann CMF (1992) Orientation to oceanic waves by green turtle hatchlings. J Exp Biol 171:1-13

* Lohmann KJ, Salmon M, Wyneken J (1990) Functional autonomy of land and sea orientation systems in sea turtle hatchlings. Biol Bull 179:214-218

Kohmann K, Swartz A, Lohmann C (1995) Perception of ocean wave direction by sea turtles. J Exp Biol 198: 1079-1085

Lohmann KJ, Witherington BE, Lohmann CMF, Salmon M (1997) Orientation, navigation, and natal beach homing in sea turtles. In: Lutz PL, Musick JA (eds) The biology of sea turtles. CRC Press, Boca Raton, FL, p 107-135

Lund U, Agostinelli C, Arai H, Gagliardi A and others (2017) Circular statistics. R Package version 0.4-7. https://cran. r-project.org/web/packages/circular/index.html

* McFarlane RW (1963) Disorientation of loggerhead hatchlings by artificial road lighting. Copeia 1963:153

Mrosovsky N, Carr A (1967) Preferences for light of short wavelengths in hatchling green sea turtles, Chelonia mydas, tested on their natural nesting beaches. Behaviour 28:217-231
Mrosovsky N, Shettleworth SJ (1968) Wavelength preferences and brightness cues in the water finding behaviour of sea turtles. Behaviour 32:211-257

* Okuyama J, Abe O, Nishizawa H, Kobayashi M, Yoseda K, Arai N (2009) Ontogeny of the dispersal migration of green turtle (Chelonia mydas) hatchlings. J Exp Mar Biol Ecol 379:43-50

* Pebesma E, Bivand R, Rowlingson B, Gomez-Rubio V and others (2017) sp: classes and methods for spatial data. R Package Version 1.2-4. https://cran.r-project.org/web/ packages/sp/index.html

Pendoley K (2005) Sea turtles and the environmental management of industrial activities in north west Western Australia. PhD thesis, Murdoch University, Perth

*Pendoley K, Kamrowski RL (2015) Influence of horizon elevation on the sea-finding behaviour of hatchling flatback turtles exposed to artificial light glow. Mar Ecol Prog Ser 529:279-288

Pendoley K, Kamrowski RL (2016) Sea-finding in marine turtle hatchlings: What is an appropriate exclusion zone to limit disruptive impacts of industrial light at night? J Nat Conserv 30:1-11

*Pendoley KL, Bell CD, McCracken R, Ball KR and others (2014) Reproductive biology of the flatback turtle Natator depressus in Western Australia. Endang Species Res 23: 115-123

*Philibosian R (1976) Disorientation of hawskbill turtle hatchlings, Eretmochelys imbricata, by stadium lights. Copeia 1976:824

Pilcher NJ, Enderby S, Stringell T, Bateman L (2000) Nearshore turtle hatchling distribution and predation. In: Pilcher N, Ismail G (eds) Sea turtles of the Indo-Pacific: research, management and conservation. ASEAN Academic Press, London, p 151-166

R Core Team (2015) R: a language and environment for statistical computing. R Foundation for Statistical Computing, Vienna

Robson NA, Hetzel Y, Whiting S, Wijeratne S, Pattiaratchi CB, Withers P, Thums M (2017) Use of particle tracking to determine optimal release dates and locations for rehabilitated neonate sea turtles. Front Mar Sci 4:173

Salmon M, Lohmann KJ (1989) Orientation cues used by hatchling loggerhead sea turtles (Caretta caretta L.) during their offshore migration. Ethology 83:215-228

* Salmon M, Wyneken J, Fritz E, Lucas M (1992) Seafinding by hatchling sea turtles: role of brightness, silhouette and beach slope as orientation cues. Behaviour 122:56-77

* Salmon M, Hamann M, Wyneken J, Schauble C (2009) Early swimming activity of hatchling flatback sea turtles Natator depressus: a test of the 'predation risk' hypothesis. Endang Species Res 9:41-47

* Santana Garcon J, Grech A, Moloney J, Hamann M (2010) Relative Exposure Index: an important factor in sea turtle nesting distribution. Aquat Conserv 20:140-149

* Scott R, Marsh R, Hays GC (2012) A little movement orientated to the geomagnetic field makes a big difference in strong flows. Mar Biol 159:481-488

* Scott R, Biastoch A, Roder C, Stiebens VA, Eizaguirre C (2014) Nano-tags for neonates and ocean-mediated swimming behaviours linked to rapid dispersal of hatchling sea turtles. Proc R Soc B 281:20141209

Silverman BW (1986) Density estimation for statistics and data analysis. Chapman and Hall, London

* Thums M, Whiting SD, Reisser JW, Pendoley KL and others (2013) Tracking sea turtle hatchlings - a pilot study 
using acoustic telemetry. J Exp Mar Biol Ecol 440: 156-163

Thums M, Whiting SD, Reisser J, Pendoley KL and others (2016) Artificial light on water attracts turtle hatchlings during their near shore transit. R Soc Open Sci 3:160142

Truscott Z, Booth DT, Limpus CJ (2017) The effect of onshore light pollution on sea-turtle hatchlings commencing their off-shore swim. Wildl Res 44:127-134

Verheijen FJ (1960) The mechanisms of the trapping effect of artificial light sources upon animals. Arch Néerl Zool 13:1-107

* Verheijen FJ (1985) Photopollution: artificial light optic spatial control systems fail to cope with. Incidents, causations, remedies. Exp Biol 44:1-18

*Verheijen FJ, Wildschut JT (1973) The photic orientation of hatchling sea turtles during water finding behaviour. Neth J Sea Res 7:53-67

Walker TA (1991) Juvenile flatback turtles in proximity to coastal nesting islands in the Great Barrier Reef province. J Herpetol 25:246-248

Walker TA, Parmenter CJ (1990) An absence of a pelagic phase in the life cycle of the flatback turtle, Natator depressa (Garman). J Biogeogr 17:275-278

Wand M (2015) Functions for kernel smoothing supporting Wand \& Jones (1995). R Package version 2.23-15. https:// cran.r-project.org/web/packages/KernSmooth/index.html

Wand MP, Jones MC (1995) Kernel smoothing. Chapman and Hall, London

Whelan CL, Wyneken J (2007) Estimating predation levels and site-specific survival of hatchling loggerhead seaturtles (Caretta caretta) from south Florida beaches. Copeia 2007:745-754

Editorial responsibility: Graeme Hays, Burwood, Victoria, Australia
Wikelski M, Kays RW, Kasdin NJ, Thorup K, Smith JA, Swenson GW Jr (2007) Going wild: what a global smallanimal tracking system could do for experimental biologists. J Exp Biol 210:181-186

Wildermann N, Critchell K, Fuentes MMPB, Limpus CJ, Wolanski E, Hamann M (2017) Does behaviour affect the dispersal of flatback post-hatchlings in the Great Barrier Reef? R Soc Open Sci 4:170164

Witherington BE (1991) Orientation of hatchling loggerhead turtles at sea off artificially lighted and dark beaches. J Exp Mar Biol Ecol 149:1-11

Witherington BE (1992) Sea-finding behavior and the use of photic orientation cues by hatchling sea turtles. PhD dissertation, University of Florida, Gainesville, FL

Witherington BE, Bjorndal KA (1991) Influences of artificial lighting on the seaward orientation of hatchling loggerhead turtles Caretta caretta. Biol Conserv 55: 139-149

Witherington BE, Martin RE (2003) Understanding, assessing, and resolving light-pollution problems on sea turtle nesting beaches, 3rd edn. Florida Marine Research Institute Technical Report TR-2

WWood S (2017) Mixed GAM computation vehicle with GCV/ AIC/REML smoothness estimation. R Package version 1.8-12. https://cran.mtu.edu/web/packages/mgcv/index. html

* Wyneken J, Salmon M (1992) Frenzy and postfrenzy swimming activity in loggerhead, green, and leatherback hatchling sea turtles. Copeia 1992:478-484

* Wyneken J, Salmon M, Lohmann CM (1990) Orientation by hatchling loggerhead sea turtles Caretta caretta L. in a wave tank. J Exp Mar Biol Ecol 139:43-50

Submitted: February 9, 2018; Accepted: May 29, 2018

Proofs received from author(s): July 20, 2018 